Revista Destaques Acadêmicos, Lajeado, v. 12, n. 1, 2020. ISSN 2176-3070

DOI: http://dx.doi.org/10.22410/issn.2176-3070.v12i1a2020.2275

http://www.univates.br/revistas

\title{
PERFIL DOS CLIENTES DE FARMÁCIA DA CIDADE DE SANTA CRUZ DO SUL/RS
}

\author{
Tiago Angelo Machado ${ }^{1}$, Fernanda Cristina Wiebusch Sindelar ${ }^{2}$
}

Resumo: No mundo capitalista e competitivo, o cliente é quem decide onde, como e o que efetivamente compra, por isso é fundamental entender os fatores que influenciam o comportamento do consumidor. Neste sentido, esta pesquisa objetivou identificar o que leva os consumidores de farmácias de Santa Cruz do Sul/RS a comprarem em uma determinada Drogaria. A metodologia foi quantitativa e bibliográfica, sendo aplicado um questionário com questões abertas e fechadas e os dados analisados por meio o Microsoft Office Excel. Analisou-se efetivamente 381 questionários, sendo uma amostra não probabilística. Os resultados demonstraram que o perfil dos consumidores são mulheres, casadas, com ensino médio completo, pertencentes a famílias compostas de três membros e que tem renda superior a quatro salários mínimos. Ainda, a preferência de compra é em redes de farmácias e o que mais influencia na decisão por determinado estabelecimento são os descontos, o atendimento e as promoções e o que menos influencia são a publicidade e o estacionamento (tanto em via pública como no próprio do estabelecimento). Algumas sugestões identificadas na pesquisa foram: necessidade de mais ofertas e promoções, mais atendentes e caixas, o que agilizaria o atendimento, maior variedade de produtos e marcas, melhorar o atendimento, oferta do serviço de tele entrega.

Palavras-chave: Decisão de compra. Farmácia. Marketing de relacionamento.

\section{INTRODUÇÃO}

Perceber as necessidades dos clientes e compreender o mercado em que atua é fundamental para garantir a sobrevivência das empresas dentro do seu setor. Para Kotler (2003), todas as empresas, de qualquer ramo, mesmo estando sozinhas no mercado (novos empreendimentos, novos produtos), tem seus concorrentes. Assim, quanto maior for o crescimento da empresa, mais atenção irá despertar e, consequentemente, irá atrair concorrentes para seu nicho de mercado.

1 Administrador. Cursando MBA em Gestão Empresarial pela Univates.

2 Orientadora. Doutora em Ambiente e Desenvolvimento pela Univates. 
Para Cobra (1997, p. 38), “a satisfação de compra está ligada a certas sensações de satisfação que o consumidor imagina estar levando a satisfação de necessidades". Assim sendo, o enriquecimento das ações promissoras em prol de um mercado melhor deve ser visto e analisado por todos que fazem parte deste contexto.

Neste intuito, refletir sobre o perfil dos clientes de farmácias da cidade de Santa Cruz do Sul/RS (SCS) auxilia a entender que clientes são esses, quais suas reais necessidades e se estas estão sendo atendidas pelas de farmácias da cidade. Destaca-se que no município em estudo estão inseridas quatro das sete maiores redes de Farmácias do Brasil (Pague Menos, DrogaRaia, Farmácias São João e Panvel), além de farmácias regionais/locais, que também tem sua força, individualidade e preços competitivos.

A partir do exposto, o problema de pesquisa estabelecido foi: quais são os fatores determinantes para escolha de uma drogaria na cidade de Santa Cruz do Sul? Para responder a problemática definiu-se como objetivo geral, identificar o que leva os consumidores de farmácias de Santa Cruz do Sul a comprarem em uma determinada Drogaria. E como objetivos específicos estabeleceu-se: identificar o perfil dos consumidores de farmácias da cidade de Santa Cruz do Sul; verificar se os clientes preferem comprar nas farmácias locais ou nas redes de farmácias; verificar o que leva os consumidores a escolherem uma determinada farmácia.

Essa pesquisa justifica-se pela importância dos resultados para o ramo farmacêutico, pois trata-se de um mercado competitivo. O comportamento do consumidor é uma função compartilhada sobre as influencias interpessoais, envolvendo familiares, amigos, colegas, entre outros, a opinião de terceiros pode interferir no comportamento e decisão de consumo (BOONE; KURTZ, 2009). Por isso analisar o comportamento do consumidor no contexto farmacêutico pode contribuir para a fidelização e melhorar o atendimento, visto a perspectiva de que a busca por atendimento em farmácias pode envolver circunstâncias de doenças e fragilidades por parte destes clientes.

\section{REFERENCIAL TEÓRICO}

A fundamentação teórica desenvolvida neste trabalho é baseada em leituras e pesquisas realizadas com o intuito de abordar o conceito de marketing, o comportamento e a decisão de compra, oportunidades de mercado e as especificidades do ramo farmacêutico. Para Vergara (2007, p. 35), "denominase referencial teórico o capítulo do projeto que tem por objetivo apresentar os estudos sobre o tema, ou especificamente sobre o problema, já realizados por outros autores". 


\subsection{Marketing}

Boone e Kurtz (2009, p. 8) definem que "a palavra Marketing incorpora um âmbito de atividades e ideias tão amplo que escolher uma definição é, muitas vezes, difícil". Para Cobra (1992), marketing não é apenas sentir o mercado ou adaptar produtos ou serviços, é preciso ir além, buscar cada vez mais proporcionar melhorias na qualidade de vida das pessoas. Segundo Kotler e Armstrong (2007, p. 3-4, grifo dos autores):

[...] marketing é administrar relacionamentos lucrativos com o cliente. Os dois principais objetivos do marketing são: atrair novos clientes, prometendo-lhes valor superior, e manter e cultivar os clientes atuais, proporcionando-lhes satisfação.

[...] de acordo com o guru da administração: 'O objetivo do marketing é tornar a venda necessária'.

[...]

Marketing envolve construir relacionamentos lucrativos e de valor com os clientes. Assim, definimos marketing como o processo pelo qual as empresas criam valor para os clientes e constroem fortes relacionamentos com eles para capturar seu valor em troca.

Enfatiza-se que as organizações procuram utilizar o marketing para criar relacionamento com o cliente, valor ao produto ou serviço e desenvolver uma perspectiva sobre a marca, de forma que ocorra a perpetuação do negócio e o sucesso do empreendimento, satisfazendo as necessidades dos clientes, bem como, surpreendendo-os quando superam suas expectativas. Para Mc Daniel (2003, p. 6), "marketing é o processo de planejar e executar a concepção, o apreçamento, a promoção e a distribuição de ideias, bens e serviços para criar trocas que satisfaçam os objetivos individuais e organizacionais". Pode-se dizer que o marketing é uma ferramenta fundamental para aproximar o cliente das organizações, identificando necessidades e estimulando desejos.

Por sua vez, Kotler (2011, p. 27) define que marketing “[...] é um processo administrativo e social pelo qual indivíduos e organizações obtém o que necessitam e desejam por meio da criação e troca de valor com os outros". Salienta-se que o marketing influência sobre a demanda de produtos, marcas, status, relacionamentos, envolvendo as necessidades e os desejos das pessoas. Ele vem da privação humana sobre alguma necessidade ou condição, das carências, dos desejos e da disposição de adquirir algo.

Churchill e Peter (2000, p. 67) determinam que marketing "é o processo de planejar e executar a concepção, estabelecimento de preços, promoção e distribuição de ideias, bens e serviços, a fim de criar trocas que satisfaçam metas individuais e organizacionais". Por sua vez, Levitt (1990, p. 53) ressalta que "marketing é a arte de conquistar a manter clientes". Diante disso, Boone e Kurtz (2009, p. 172) revelam que "os profissionais de marketing tentam estimular esse sentimento de urgência fazendo uma necessidade ser sentida 
e, então, influenciando a motivação dos consumidores para satisfazer a suas necessidades comprando produtos específicos".

$\mathrm{Na}$ busca do diferencial, as empresas utilizam-se da inteligência e da estratégia para superarem as expectativas dos clientes, para tal, trabalham os $4 \mathrm{P}^{\prime}$ s do marketing ou composto de marketing ou, ainda, mix de marketing que envolve quatro elementos: produto, preço, praça (distribuição) e promoção.

A utilização de um composto de marketing adequado pressupõe o conhecimento correto das variáveis ambientais de natureza tecnológica, econômica, psicológica, social, política, legal, etc. Isso significa que a organização pode segmentar devidamente o mercado e posicionar corretamente seu bem (ou serviço), o que terá como consequência, muito provavelmente, a satisfação do cliente (CAMPOMAR; IKEDA, 2006, p. 11).

Utilizando-se dos $4 \mathrm{P}^{\prime}$ s do marketing, as organizações buscam criar valor, de forma que o produto certo, esteja no local apropriado, tendo um preço atraente e uma promoção adequada (FUTRELL, 2003). A definição dos $4 \mathrm{P}^{\prime}$ 's do marketing são produto, preço, praça e promoção. Em que o produto "consiste em criar algo novo [...]. A invenção de produto é uma estratégia que envolve custos, mas os resultados podem ser grandes" (KOTLER, 2011, p. 370). O preço compreende "a quantia em dinheiro que se cobra por um produto ou serviço, representando [...] a soma de todos os valores que os consumidores trocam pelos benefícios de obter ou utilizar um produto ou serviço [...], de tal modo que ele é o único elemento que produz receita" (KOTLER; ARMSTRONG, 2007, p. 258).

A praça ou canal de distribuição objetiva "tornar um produto ou serviço disponível para o consumo ou uso por um consumidor final ou usuário organizacional" (KOTLER; ARMSTRONG, 2007, p. 305). Já a promoção, na compreensão de Campomar e Ikeda (2006, p. 28), "é um título amplo dado às técnicas utilizadas para aumentar a consciência, reconhecimento, conhecimento e informação do consumidor a respeito do produto, marca ou da organização". Existem fatores que influenciam no comportamento do consumidor, por isso, na próxima seção aborda-se estes fatores.

\subsection{Fatores que influenciam o comportamento do consumidor}

A demanda por determinado produto ou serviço tem influência direta na necessidade de aquisição do consumidor. Ferrel e Hartline (2008, p. 113) definem que:

[...] uma estratégia de marketing bem sucedida depende [...] de uma clara compreensão de quem são os consumidores, do que precisam, o que preferem e por que compram. Embora essa compreensão seja obviamente pertinente para planejar a oferta do produto, também 
causa impacto nas decisões de precificação, distribuição e promoção do programa de marketing

[...] O processo de compra [...] começa com o reconhecimento de uma necessidade, depois atravessa os estágios da busca de informações, avaliação das alternativas, decisão de compra e avaliação póscompra.

Destaca-se que há quatro fatores que influenciam no processo de compra. Os fatores sociais envolvem a influência direta ou indireta sobre atitudes e comportamentos do indivíduo, atuando sobre as escolhas de marcas ou produtos, na autoimagem, nas atitudes e no estilo de vida. A influência direta é exercida por grupos de afinidade, podendo estes serem primários (família, amigos, vizinhos) ou secundários (grupos religiosos, associações de classe, grupos profissionais). A influência indireta pode ocorrer por grupos de aspirações (o qual espera pertencer) e grupos de dissociações (o qual os valores e comportamentos são rejeitados) (KOTLER; KELLER, 2006).

Ainda, tem-se os fatores culturais, que são subdivididos em três subfatores, ao que Churchill e Peter (2000) definem: cultura que envolve os valores e o comportamento das pessoas na vida em sociedade e que aumentam a probabilidade de sobrevivência social. Já a subcultura engloba os grupos distintos que compartilham valores e padrões, diferenciando-se entre estes grupos (nacionalidades, religiões, raças, regiões geográficas, sexo, ocupação, comunidades). E, finalmente, as classes sociais referem-se as hierarquias de status em que as pessoas são classificadas baseadas no prestígio e valor (riqueza, habilidade e poder).

Já os fatores pessoais envolvem as decisões tomadas no decorrer da vida do indivíduo sendo influenciado pela idade, ocupação, situações econômicas, personalidade, estilo de vida, crenças, valores e a própria imagem. Neste sentido, as empresas devem considerar as mudanças e transições na vida do indivíduo para perceber novas necessidades (KOTLER; KELLER, 2006).

Por fim, tem-se os fatores psicológicos, que Kotler e Keller (2006) dividem em quatro. A motivação envolve a intensidade que motiva a alcançar determinada necessidade. A percepção é caracterizada pelo processo em que a pessoa seleciona, organiza e interpreta as informações recebidas, criando uma imagem do mundo ao seu redor. Por sua vez, a aprendizagem consiste nas mudanças de comportamento em decorrência de ações, aprendizagens e experiências. Já a memória avaliza que as informações e experiências individuais garantam a busca por serviços ou produtos (ou não), bem como, mantem marcas na memória das pessoas.

Outrossim, a compreensão sobre os fatores que influenciam o comportamento do consumidor é crucial para entender a tomada de decisão sobre determinado produto ou serviço, a escolha e efetiva compra ocorre por meio de processos e etapas, que serão abordados a seguir. 


\subsection{Decisão de compra}

A decisão de compra passa por um processo, que Kotler e Keller (2006, p. 172) definem como:

O campo do comportamento do consumidor estuda como as pessoas, grupos e organizações selecionam, compram, usam e descartam artigos, serviços, ideias ou experiências para satisfazer suas necessidades ou desejos. Estudar o cliente ajuda a melhorar ou lançar produtos e serviços, determinar preços, projetar canais, elaborar mensagens e desenvolver outras atividades de marketing.

Este processo tem cinco etapas: reconhecer o problema, buscar informação, avaliação das alternativas, decisão de compra e comportamento pós-compra. Assim sendo, a etapa do reconhecimento do problema envolve a percepção de uma necessidade, o impulso, a motivação de supri-la (CHURCHILL; PETER, 2000). Neste ponto, os profissionais de marketing devem saber o que motiva os consumidores e atender estas motivações.

No momento em que o cliente busca informações, percebe-se que há quatro fontes para esta etapa: pessoais (família, amigos, vizinhos e conhecidos); comerciais (sites, propagandas, embalagens, vendedores, etc.); públicas (comunicação em massa, classificação de consumo em órgãos, etc.) e experimentais (uso do produto/serviço, manuseio, exame, etc.) (KOTLER; KELLER, 2006).

No que se refere ao processo de avaliação de alternativas, os autores Kotler e Keller (2006) segmentam-na em: a) crenças e atitudes, em que a atitude faz referência às avaliações, sentimentos e tendências; já as crenças relacionamse a maneira de pensar a respeito de algo, envolvendo os atributos e benefícios do produto/marca/serviço; b) modelo de expectativa em relação ao valor em que o indivíduo avalia o produto ou serviço sob a ótica da importância, ou seja, avalia-se o custo-benefício oferecido pelo produto ou serviço (KOTLER; KELLER, 2006).

A efetiva decisão de compra caracteriza-se como o momento em que o indivíduo decide ou não fazer uma compra, o que, onde, quando comprar e como realizará o pagamento (CHURCHILL; PETER, 2000). Os fatores que interferem e afetam a decisão de compra são: a) modelos não compensatórios de escolha do consumidor, em que se compara os atributos positivos e negativos entre marcas, estabelecimentos, serviços, produtos; b) fatores de interferência, ocorrem quando há mudança de decisão decorrente de atitudes dos outros e fatores situacionais imprevistos calculados pelos riscos (risco funcional, risco físico, risco financeiro, risco social, risco psicológico e risco de tempo) (KOTLER; KELLER, 2006).

Ainda, existe a etapa do comportamento pós-compra, na qual Churchill e Peter (2000, p. 151, grifo dos autores), destacam que "[...] avaliação pós- 
compra é decisiva [...], pois, se um consumidor tem repetidamente experiências favoráveis com determinada marca, pode desenvolver lealdade a ela". Para Kotler e Keller (2006) há três etapas no comportamento pós-compra: primeiro, a satisfação pós-compra que envolve as expectativas dos clientes sobre um produto ou serviço e a performance percebida. Segundo, as ações pós-compra, associados a satisfação ou insatisfação. E, terceiro, a utilização pós-compra e descarte vinculada a taxa de consumo, em que quanto mais rápido o consumo, mais rápido ocorrerá a nova compra.

Após entender como ocorre a decisão de compra, para fins desta pesquisa, é necessário abordar o mercado farmacêutico, o setor foco deste estudo.

\subsection{O mercado farmacêutico}

Há pontos que precisam ser considerados pelas empresas para avaliar o serviço ou produto oferecido no mercado, como a concorrência que conforme Cobra (1992), a concorrência é importante para que as empresas evoluam, procurem melhorar seus serviços e proporcionar a seus clientes, melhores produtos.

Além disso, é fundamental avaliar as oportunidades no mercado concorrencial, entender o que está ou não sendo feito ou oferecido, neste contexto, Cobra (2012, p. 74) enfatiza que "quando abordamos a avaliação das oportunidades de mercado, referimo-nos não somente a identificação de desejos e necessidades, mas também ao desenvolvimento de estratégias e programas para converter clientes potenciais em clientes atuais".

Assim sendo, a indústria farmacêutica envolve muita pesquisa, desenvolvimento e tecnologia. Segundo ANVISA (2018) e Guimarães (2018), as dez empresas farmacêuticas detêm $40 \%$ da fatia de mercado (EMS, Hypermarcas, Sanofi, Novartis, Aché, Eurofarma, Takeda Pharma, Bayer, Teuto Brasileiro e GSK). Nos últimos anos, a indústria farmacêutica vem aumentando de maneira exponencial seus custos, especialmente decorrente de novos projetos e medicamentos em fases finais de desenvolvimento. Em se tratando de Brasil, em 2017, a comercialização de medicamentos faturou em torno de $\mathrm{R} \$$ 69,5 bilhões, sendo que 2/3 referem-se às farmácias de varejo (ANVISA, 2018; GUIMARÃES, 2018). A indústria brasileira deste setor tem 492 empresas farmacêuticas, em que 123 são multinacionais e 396 são nacionais (SOUZA; BATISTA, 2018).

Ainda, segundo a Febrafar (2019), a estimativa de crescimento em 2019 é de $10 \%$ no faturamento das farmácias locais/regionais e $20 \%$ nas farmácias associativistas (de redes). Porém a entidade destaca que os consumidores estão cada vez mais exigentes, exigindo profissionalização no atendimento nas lojas, preços e qualidade, tanto dos serviços como dos produtos, enfatizando 
que "como em qualquer mercado, apenas obterão destaque as farmácias que buscarem por uma maior adequação" (FEBRAFAR, 2019, texto digital).

Nesta mesma perspectiva, Strouts (2018) enfatiza que a atividade farmacêutica vem sofrendo mudanças constantes, quebrando os paradigmas antigos de operação desse negócios, tendo em vista, principalmente, a inserção do ambiente tecnológico. Desta forma, evidenciam-se ambientes biofarmacêuticos, uso de dispositivos médicos e de diagnósticos, inovação, aplicação de ciência de dados, o que pode culminar em maior velocidade de comercialização (por meio de sites e aplicativos, por exemplo) e engajamento dos pacientes na busca de oportunidades (preços, promoções, localização, etc.).

\section{PROCEDIMENTOS METODOLÓGICOS}

Oliveira (1998) esclarece que o uso de metodologia em uma pesquisa busca abrir horizontes e definir diretrizes fundamentais para o desenvolvimento do estudo. Saber escolher a metodologia certa é fundamental para se ter um resultado com qualidade no objetivo desejado.

Assim sendo, esta pesquisa foi quantitativa. Conforme Malhotra (2006), a pesquisa quantitativa procura mensurar os dados e tornar mais amplo os resultados da amostra para a população alvo. Ainda, segundo Mc Daniel (2003), na pesquisa quantitativa, o resultado é voltado para análise matemática, preferencialmente com uma amostragem grande. Para tal, o estudo buscou encontrar os resultados sobre itens pré-estabelecidos: identificar o perfil dos consumidores de farmácias, descobrir qual foi a última farmácia que efetuou suas compras; verificar se o produto que está sendo procurado na farmácia, tem no momento; descobruir se o cliente tem o hábito de comprar nas farmácias do bairro ou não.

Também envolveu levantamento bibliográfico, que, para Mattar (2001), é uma das melhores formas de amadurecer ou aprofundar uma pesquisa, por meio da verificação de livros já existentes sobre determinado assunto. No entendimento de Vergara (2007, p. 48) a "pesquisa bibliográfica é o estudo sistematizado desenvolvido com base em material publicado em livros, revistas, jornais, redes eletrônicas, isto é material acessível ao público em geral".

A população alvo deste envolveu clientes de farmácias que residem na cidade de Santa Cruz do Sul/RS. Destaca-se que, "uma população é um grupo de pessoas ou empresas que interessa entrevistar para o propósito específico de um estudo" (ROESCH, 1999, p. 138).

A coleta de dados foi realizada no período de 14 de abril a 15 de maio de 2019, por meio de questionário com perguntas abertas e fechadas, sendo que conforme Malhotra (2006, p. 182), no "questionário os entrevistados devem responder o que foi feito para elucidar informações específicas". Para tal, o pesquisador disponibilizou o questionário utilizando-se do Formulário do Google, enviando ao público alvo por meio das redes sociais e rede de 
relacionamentos, também foi contratada um pesquisador que atuou no envio destes questionários por meio dos mesmos meios (redes sociais e de relacionamentos). A amostra foi não probabilística, em que os elementos da amostragem compõem-se de forma intencional, não garantindo a representatividade do universo (BARROS; LEHFELD, 2002).

Por fim, para a análise de dados foram excluídos da pesquisa os respondentes que não residem em Santa Cruz do Sul/RS. Foi utilizado o software Microsoft Office Excel, em que as informações foram tabuladas e analisadas em gráficos e tabelas. Foram coletados 393 respostas, sendo descartadas 12 questionários por serem de residentes de outras cidades, analisando-se 381 questionários de forma efetiva.

\section{ANÁLISE DE RESULTADOS}

Por meio do questionário buscou-se identificar o perfil dos clientes das farmácias de Santa Cruz do Sul-RS. Diante disso, o perfil dos respondentes revela que a grande maioria têm entre 31 e 40 anos (31\%), já $23 \%$ têm entre 41 e 50 anos, $22 \%$ entre 21 e 30 anos, $15 \%$ acima e 51 anos e $8 \%$ têm até 20 anos. Com relação ao sexo, a maioria são mulheres (66\%), ante $32 \%$ de homens e $2 \%$ não identificaram o sexo. Além disso, 39\% são casados, 33\% solteiros, $15 \%$ estão em união estável, $5 \%$ identificaram-se como separados, $4 \%$ divorciados e $4 \%$ viúvos.

Em relação a escolaridade dos respondentes, identificou-se que $28 \%$ têm ensino médio completo, $23 \%$ têm ensino superior, $19 \%$ têm ensino superior incompleto, $18 \%$ são pós-graduados, $5 \%$ não concluíram o ensino médio, $5 \%$ têm ensino fundamental completo, 3\% têm pós-graduação incompleto e $1 \%$ não concluíram o ensino fundamental, não houve respondentes analfabetos.

Outro fator avaliado foi o número de pessoas que residem na moradia da família, em que 32\% têm três moradores, 31\% têm dois moradores, $20 \%$ têm quatro, $12 \%$ moram sozinhos e apenas $4 \%$ residem com cinco ou mais pessoas.

Ainda, com relação a renda, $40 \%$ têm renda familiar acima de quatro salários mínimos, $28 \%$ têm renda entre três e quatro salários mínimos, $20 \%$ têm renda entre dois e três salários mínimos, $10 \%$ percebem renda entre um e dois salários e $2 \%$ têm renda de até um salário mínimo.

Quando questionados, por meio de uma questão aberta, sobre suas profissões, os respondentes mencionaram 82 profissões (TABELA 1). Destacando-se as profissões com maior incidência de vendedor, enfermeiro, estudante, aposentado, sem profissão definida (desempregados, do lar ou não identificaram uma profissão), professores, empresários, funcionários públicos e técnicos de enfermagem. 


\begin{tabular}{lcc}
\hline Profissão & Número & Percentual \\
\hline Vendedor & 27 & $7,1 \%$ \\
Enfermeiro & 25 & $6,6 \%$ \\
Estudante & 25 & $6,6 \%$ \\
Aposentado & 20 & $5,2 \%$ \\
Sem Profissão & 20 & $5,2 \%$ \\
Professor & 18 & $4,7 \%$ \\
Empresário & 15 & $3,9 \%$ \\
Servidor Público & 11 & $2,9 \%$ \\
Técnico Enfermagem & 10 & $2,6 \%$ \\
Outras atividades & 210 & $55,1 \%$ \\
\hline TOTAL & $\mathbf{3 8 1}$ & $\mathbf{1 0 0 , 0} \%$ \\
\hline
\end{tabular}

Fonte: Elaborado pelos autores.

No âmbito do conhecimento específico relativo ao serviço farmacêutico, buscou-se identificar a farmácia que frequentemente os respondentes buscam, sendo as mais procuradas: Farmácias São João (64\%), DrogaRaia (13\%), Panvel (12\%), Maxxi Econômica (6\%), também foram citadas as farmácias Associadas (1\%), UltraMed (1\%), Agafarma $(0,5 \%)$, Big $(0,5 \%)$, Droga Seis $(0,5 \%)$, Vida Farmácias $(0,5 \%)$, Confiança $(0,3 \%)$, Farmamelitus $(0,3 \%)$, IntraMed $(0,3 \%)$. Ainda, houve respondentes que disseram procurar várias farmácias. Por meio destas respostas, percebeu-se que a maioria dos respondentes buscam farmácias de redes (99\%) e apenas $1 \%$ dos respondentes efetuam suas compras nas farmácias locais.

Com relação a frequência de compra, $40 \%$ dos respondentes afirmou que busca uma farmácia uma vez por mês, 31\% frequentam os estabelecimentos a cada 15 dias, $14 \%$ vão a farmácia semanalmente, $13 \%$ frequentam menos de uma vez por mês e $2 \%$ vão mais de uma vez por semana à farmácia. Além disso, os entrevistados também foram questionados se estão satisfeitos com a farmácia onde costumam realizar suas compras, sendo que $91 \%$ responderam que sim, $8 \%$ talvez e, apenas, $1 \%$ responderam que não.

No contexto da influência na decisão por determinado estabelecimento comercial, pode-se enfatizar que a maior influência neste contexto envolve os descontos oferecidos, o atendimento, as promoções, a variedade de produtos, a diversidade de marcas e a localização (TABELA 2). 
Tabela 2 - Grau de influência na decisão de compra

\begin{tabular}{lccccccc}
\hline \multicolumn{1}{c}{ Motivos da decisão de compra } & $\mathbf{1}$ & $\mathbf{2}$ & $\mathbf{3}$ & $\mathbf{4}$ & $\mathbf{5}$ & Média & $\begin{array}{c}\text { Desvio- } \\
\text { Padrão }\end{array}$ \\
\hline $\begin{array}{l}\text { Descontos oferecidos pelo } \\
\text { estabelecimento }\end{array}$ & 27 & 19 & 88 & 81 & 166 & 3,89 & 0,49 \\
$\begin{array}{l}\text { Estacionamento para clientes } \\
\text { Facilidade de estacionar na via }\end{array}$ & 58 & 33 & 91 & 91 & 108 & 3,41 & 0,90 \\
pública & 65 & 42 & 107 & 99 & 68 & 3,17 & 0,74 \\
Localização & 24 & 17 & 94 & 116 & 130 & 3,82 & 0,30 \\
Variedade de produtos & 23 & 22 & 88 & 110 & 138 & 3,83 & 0,34 \\
Diversidade de marcas & 23 & 28 & 85 & 115 & 130 & 3,79 & 0,36 \\
Atendimento & 25 & 20 & 77 & 113 & 146 & 3,88 & 0,37 \\
Facilidade de pagamento & 36 & 26 & 82 & 108 & 129 & 3,70 & 0,59 \\
Promoções & 23 & 23 & 92 & 104 & 139 & 3,82 & 0,36 \\
Segurança & 35 & 41 & 91 & 109 & 105 & 3,55 & 0,57 \\
Tempo de espera no atendimento & 25 & 29 & 105 & 116 & 106 & 3,65 & 0,33 \\
Espaço físico da farmácia & 32 & 35 & 81 & 112 & 121 & 3,67 & 0,54 \\
Publicidade (anúncios, redes & 70 & 50 & 121 & 77 & 63 & 3,03 & 0,73 \\
sociais, ...) & & & & & & \\
\hline
\end{tabular}

Fonte: Elaborado pelos autores.

Os fatores que mais influenciam na decisão de compra envolvem todos os $4 \mathrm{P}^{\prime}$ 's de marketing, destacando-se o preço, que de acordo com Kotler e Armstrong (2007) refere-se ao valor desembolsado pelo produto/serviço, frequentemente percebidos nos descontos ofertados nas farmácias. Já o que menos influenciam são a publicidade, a disponibilidade de estacionamento (público ou privado), facilidade no pagamento e a segurança.

Com o estudo também buscou-se entender que tipos de produtos os respondentes habitualmente adquirem quando se deslocam até a farmácia (GRÁFICO 1). Neste contexto, os produtos de higiene (27\%) e medicamentos que não necessitam receita $(25 \%)$ foram os mais procurados. Além disso, $14 \%$ buscam medicamentos de uso contínuo, 13\% procuram cosméticos, $11 \%$ adquirem produtos controlados, $6 \%$ procuram as farmácias para medicamentos que não necessitam receituário e não são contínuos e controlados, e $4 \%$ que fazem recarga de celular. Também, disponibilizou-se a opção de Outros, em que o respondente poderia escrever sua resposta e percebeu-se que $0,5 \%$ buscam produtos de uso infantil (fraldas, leite, produtos de higiene infantil, etc.). 
Gráfico 1 - Produtos que habitualmente adquirem

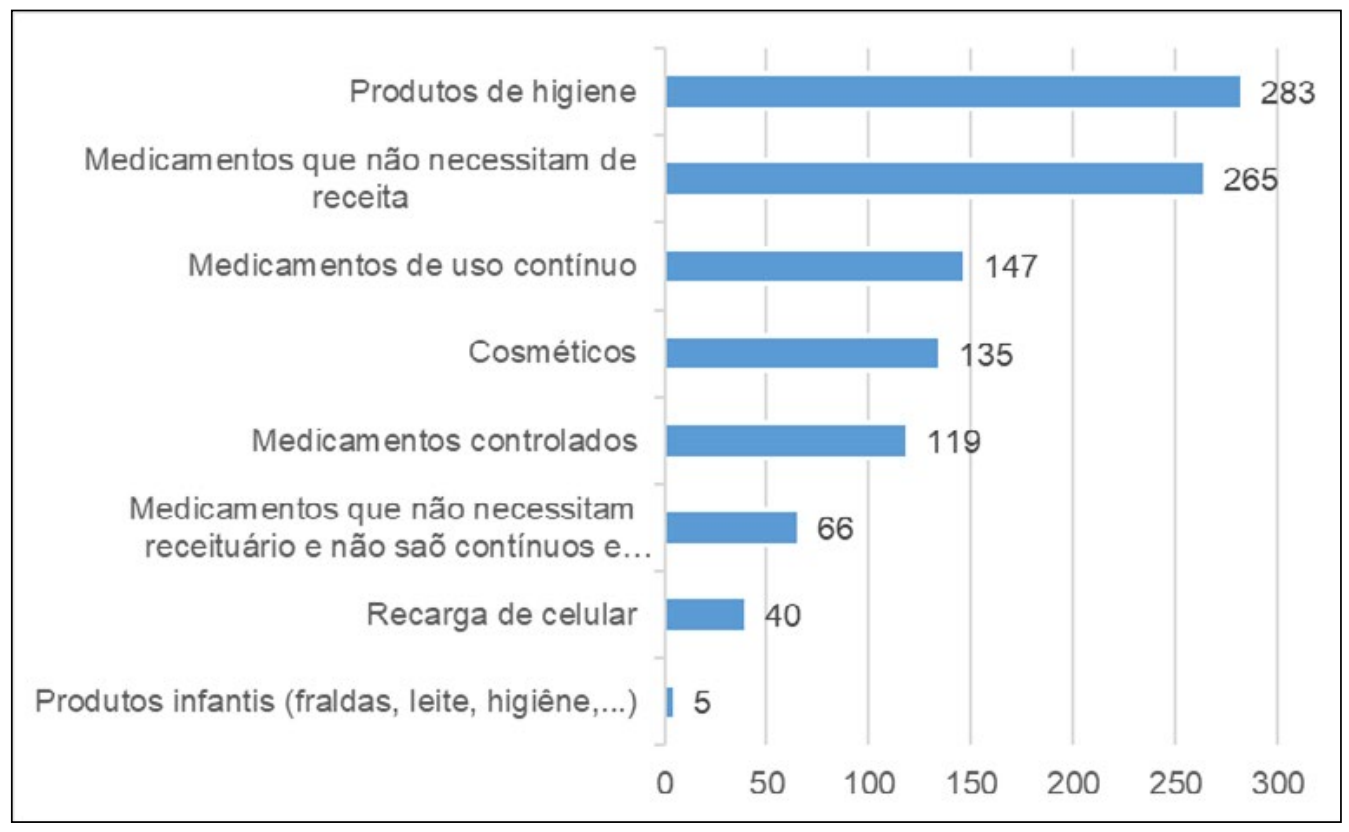

Fonte: Elaborado pelos autores.

Ao serem questionados se indicariam a farmácia que habitualmente frequentam para outras pessoas do seu convívio percebeu-se que $92 \%$ indicariam, 4\% não indicariam, 3\% talvez e 1\% disseram não ter resposta para a questão. Assim, pode-se inferir que os frequentadores das farmácias de SCS podem influenciar diretamente na compra de outrem, visto que a influência direta envolve as sofridas por familiares, amigos, colegas, conforme destacado por Kotler e Keller (2006).

As pessoas que responderam que indicariam, evidenciaram que entre os motivos para tal atitude estão o bom atendimento $(37,5 \%)$, preços bons $(16,3 \%)$, variedade de produtos /marcas $(11,0 \%)$, descontos e promoções $(7,0 \%)$, a farmácia ser boa ou ótima $(5,8 \%)$, encontrar o que precisa em decorrência de ter estoque dos produtos $(4,9 \%)$, boa localização $(4,4 \%)$, terem confiança na farmácia $(2,3 \%)$ (TABELA 3$)$.

Tabela 3 - Motivos da indicação

\begin{tabular}{lrr}
\hline Motivos da indicação & Número & Percentual \\
\hline Bom/ágil atendimento & 129 & $37,5 \%$ \\
Bons preços & 56 & $16,3 \%$ \\
Variedade de produtos/marcas & 38 & $11,0 \%$
\end{tabular}




\begin{tabular}{lrr}
\hline Motivos da indicação & Número & Percentual \\
\hline Descontos e promoções & 24 & $7,0 \%$ \\
Boa/ótima farmácia & 20 & $5,8 \%$ \\
Estoque de produtos & 17 & $4,9 \%$ \\
Boa localização & 15 & $4,4 \%$ \\
Confiança & 8 & $2,3 \%$ \\
Ambiente organizado & 7 & $2,0 \%$ \\
Qualidade dos serviços e produtos & 5 & $1,5 \%$ \\
Ambiente limpo/agradável/tranquilo & 4 & $1,2 \%$ \\
Condições de pagamento & 3 & $0,9 \%$ \\
Excelente farmacêutico/equipe & 3 & $0,9 \%$ \\
Outros motivos & 15 & $4,4 \%$ \\
\hline TOTAL & 344 & $\mathbf{1 0 0 , 0 \%}$ \\
\hline
\end{tabular}

Fonte: Elaborado pelos autores.

Com relação ao respondentes que não indicam, também elencou-se os motivos desta atitude, destacando-se que a farmácia deveria melhorar o atendimento $(23,8 \%)$, não têm preferência em alguma farmácia específica para indicar $(14,3 \%)$, não fazem indicação $(9,5 \%)$, fatores relacionados a localização $(9,5 \%)$, como a farmácia estar em algum bairro. Outros fatores foram pontuais a apenas um indivíduo e estão relacionados no Gráfico 2.

Gráfico 2 - Motivos da não indicação

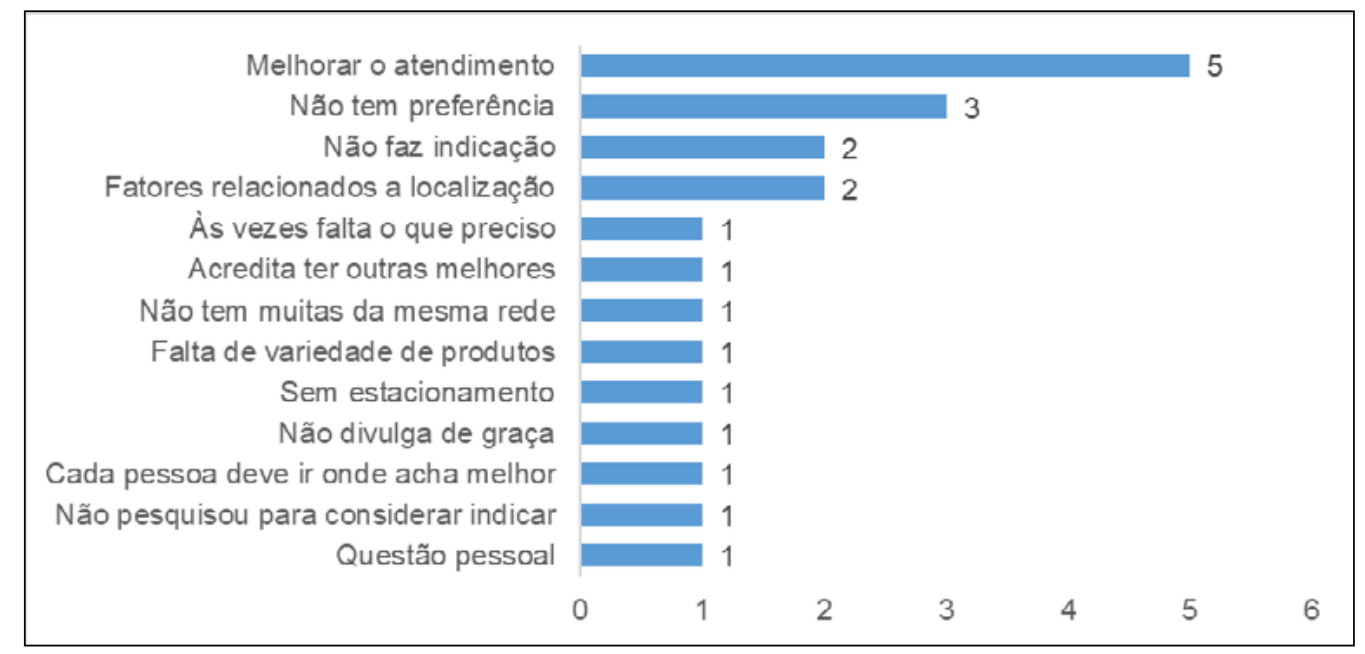

Fonte: Elaborado pelos autores. 
Também se considerou a perspectiva tecnológica, questionandose os respondentes quanto a realização de compras pela internet no ramo farmacêutico, sendo que $88 \%$ nunca tiveram esta experiência, entretanto, destes $1 \%$ comentou que adorariam adquirir seus produtos por meio de farmácias virtuais. Destarte, $12 \%$ já tiveram esta experiência, ao que identificou-se que alguns não tiveram boas experiências $(20 \%)$ em decorrência das respostas "não adquiriria novamente" ou "prefere a farmácia física pelo atendimento", do contrário há respondentes que voltariam a realizar compras em farmácias virtuais $(80 \%)$, dos quais alguns evidenciaram ser em decorrência dos preços e praticidade.

Por fim, solicitou-se que os entrevistados deixassem suas sugestões, caso tivessem, 53\% dos respondentes não tinham sugestões. Assim, analisouse as sugestões dos outros $47 \%$ (TABELA 4 ), em que $14,5 \%$ sugerem ter mais promoções e ofertas, $6,8 \%$ declararam que deveria ter mais atendentes ou caixas para o atendimento, $6,8 \%$ pediram para aumentar a variedade de produtos e marcas, 6,3\% sugerem que se deveria agilizar ou melhorar o atendimento, 5,8\% de ter estacionamento nos estabelecimentos, 5,8\% enfatizam que a farmácia poderia oferecer tele entrega ou que esta poderia ser gratuita, $5,3 \%$ pedem a melhoria nos preços praticados pela farmácia, $48 \%$ sugerem o aumento do horário de atendimento, atendimento $24 \mathrm{~h}$ ou atendimento nos domingos e feriados.

Tabela 4 - Sugestões

\begin{tabular}{lrr}
\hline \multicolumn{1}{c}{ Sugestão } & Número & Percentual \\
\hline Mais ofertas/promoções & 30 & $14,5 \%$ \\
Aumentar a variedade de produtos/marcas & 14 & $6,8 \%$ \\
Mais atendentes e caixas & 14 & $6,8 \%$ \\
Agilizar/melhorar o atendimento & 13 & $6,3 \%$ \\
Ter estacionamento & 12 & $5,8 \%$ \\
Tele entrega & 12 & $5,8 \%$ \\
Melhorar os preços & 11 & $5,3 \%$ \\
Horário de atendimento & 10 & $4,8 \%$ \\
Cartão/Planos fidelidade com descontos para clientes fiéis & 9 & $4,3 \%$ \\
Treinamento aos atendentes & 9 & $4,3 \%$ \\
Aumentar a loja/espaço físico e melhorar a fachada & 8 & $3,9 \%$ \\
Não oferecer vitaminas ou insistir em outros produtos & 7 & $3,4 \%$ \\
Oferecer compra online/aplicativo & 6 & $2,9 \%$ \\
Atendentes mais simpáticos & 6 & $2,9 \%$ \\
Mais estoque de produtos & 6 & $2,9 \%$
\end{tabular}




\begin{tabular}{lrr}
\hline \multicolumn{1}{c}{ Sugestão } & Número & Percentual \\
\hline Ter farmácias em bairros & 5 & $2,4 \%$ \\
Ter senha & 4 & $1,9 \%$ \\
Atendentes com maior conhecimento & 4 & $1,9 \%$ \\
Aumentar o estacionamento & 3 & $1,4 \%$ \\
Melhorar o ar condicionado & 3 & $1,4 \%$ \\
Outras sugestões & 21 & $10,1 \%$ \\
\hline TOTAL & $\mathbf{2 0 7}$ & $\mathbf{1 0 0 , 0} \%$ \\
\hline
\end{tabular}

Fonte: Dos autores (2019).

Realizou-se análises cruzadas considerando a idade entre 31 e 40 anos (maior percentual dos respondentes, 118 respondentes) e grau de influência na compra (marcado com 5 em todos os critérios), ao que identificou-se que três fatores que mais influenciam na compra destes respondentes envolvem os descontos oferecidos (57), a variedade de produtos (54) e as promoções (53). Já os que menos influenciam (marcado com 1 em todos os critérios) são a publicidade (30), a facilidade de estacionamento em via pública (24) e o estacionamento para clientes (17). Os respondentes desta faixa etária costumam ir à farmácia mensalmente.

Já para as pessoas mais velhas (acima de 50 anos - 61 respondentes), que costuma ir à farmácia quinzenalmente, o que mais influência na decisão de compra é o atendimento dos atendentes e farmacêuticos (26), os descontos (22), a variedade de produtos (21), bem como, a localização (21). E com menor influência tem-se estacionamento para clientes (9), publicidade (8) e facilidade de estacionar em via pública.

Outrossim, se considerar o público feminino (250 respondentes), que geralmente costuma comprar na farmácia mensalmente, o grau de influência na compra, os três fatores com maior incidência respectivamente são os descontos oferecidos (118), a variedade de produtos (96) e as promoções (96). Já os três com menor influência são a publicidade (44), o estacionamento para clientes (42) e a facilidade de estacionar em via pública (42).

$\mathrm{Na}$ mesma perspectiva, considerando o público masculino (123 respondentes) os fatores que mais influenciam nas compras são o atendimento dos atendentes farmacêuticos (50), os descontos (48) e a localização (44). Com menor influência tem-se publicidade (26), facilidade de estacionar em via pública (23) e estacionamento para clientes (16). Da mesma forma, a frequência de compras é mensal.

Por meio da pesquisa é possível identificar que normalmente as pessoas buscam atendimento em farmácias mensalmente, sendo que a maior procura concentra-se em produtos de higiene e medicamentos que não necessitam de receita médica. Outrossim, a decisão de compra e escolha da farmácia tem forte 
ligação com as promoções, descontos e preços ofertados pelas farmácias, o que justificaria a preferência pelas redes de farmácias, que adquirem em volume e conseguem ter maior barganha no mercado.

\section{Considerações Finais}

Destaca-se que todos os objetivos propostos nesta pesquisa foram atingidos em sua totalidade. O primeiro objetivo buscou identificar o perfil dos consumidores de farmácias da cidade de SCS, pondera-se que o público feminino e adultos são os que mais frequentam estabelecimentos farmacêuticos, a maioria são pessoas casadas, com ensino médio completo e residem com uma constituição familiar de três membros. Percebe-se que a renda familiar dos respondentes pode ser considerada alta, acima de quatro salários mínimos, sendo que grande parte destes atua no comércio, na área da saúde, da educação ou funcionalismo público, e ainda há um relevante número de respondentes que estão estudando, são aposentados, empresários ou não têm uma profissão (desempregados, do lar ou sem profissão).

Com relação ao objetivo de verificar se os clientes preferem comprar nas farmácias locais ou nas redes de farmácias, foi possível perceber que as redes de farmácias são as mais frequentadas pelos respondentes (principalmente, São João, DrogaRaia, Panvel e Maxxi Econômica), ou seja, preferem redes de farmácias. Identificou-se que produtos de higiene e medicamentos que não necessitam de receita são os produtos mais adquiridos nas farmácias. Ainda, os entrevistados evidenciam que buscam atendimento em farmácias uma ou duas vezes ao mês e a maioria está satisfeita com a farmácia de sua preferência. Além disso, 88\% nunca realizaram compra por meio eletrônico em farmácias. Ao mesmo tempo que $92 \%$ indicariam a farmácia de sua preferência para outras pessoas.

A respeito do objetivo de verificar o que leva os consumidores a escolherem uma determinada farmácia, evidenciou-se que os descontos, o atendimento e as promoções são os fatores que mais influenciam na decisão de compra em determinado estabelecimento. Já a publicidade e o estacionamento (tanto em via pública como no próprio do estabelecimento) são os que menos influenciam na decisão por uma farmácia. No âmbito das sugestões o que mais se destaca é a necessidade de mais ofertas e promoções, mais atendentes e caixas, o que agilizaria o atendimento também (outro fator sugerido), maior variedade de produtos e marcas, melhorar o atendimento, oferta do serviço de tele entrega e este serviço ser gratuito.

Realizou-se cruzamento de alguns dados e percebeu-se que as pessoas com mais idade buscam melhor atendimento e frequentam as farmácias quinzenalmente, enquanto o grupo com idade entre 31 e 40 anos (maior percentual de respondentes) buscam descontos, promoções e variedade de produtos, tendo frequência mensal no serviço farmacêutico. Em se tratando 
das diferenças entre o público feminino (maior percentual) e masculino, os dois públicos buscam por bom atendimento, descontos e primam pela localização na hora de decidir sobre o estabelecimento onde comprar.

Por fim, enfatiza-se que este estudo limita seus resultados ao município de SCS, podendo não representar os mesmos percentuais em outras regiões do país ou mundo. Ainda, em decorrência da aplicação se dar em ambiente digital, pode-se ter limitado as respostas a um público direcionado, pois nem todos os frequentadores de farmácias podem ter redes sociais. Sendo uma amostragem não probabilística, é possível que a amostra não coincida com resultados que possam ser encontrados por meio de um levantamento por censo, por exemplo.

\section{Referências}

AGÊNCIA NACIONAL DE VIGILÂNCIA SANITÁRIA (ANVISA). Anuário estatístico do mercado farmacêutico. Brasília: Anvisa, 2018.

BARROS, Aidil de J. P.; LEHFELD, Neide A. S. Projeto de pesquisa: propostas metodológicas. 13. ed. Petrópolis: Vozes, 2002.

BOONE, Louis E; KURTZ, David L. Marketing Contemporâneo. São Paulo: Cengage Learning, 2009.

STROUTS, Poul. Novas formas de trabalho no mercado farmacêutico. Farmacêuticas, $31 \mathrm{dez}$. 2018. Disponível em: <http://www.farmaceuticas.com.br/novas-formas-detrabalho-no-mercado-farmaceutico/>. Acesso em: 16 jun. 2019.

FEBRAFAR. Mercado farmacêutico 2019: veja expectativas. 04 jan. 2019. Disponível em: <https://www.febrafar.com.br/mercado-farmaceutico-2019-veja-expectativas/>. Acesso em: 15 jun. 2019.

CAMPOMAR, Marcos Cortez; IKEDA, Ana Akemi. O planejamento de marketing e a confecção de planos: dos conceitos a um novo produto. São Paulo: Saraiva, 2006.

CHURCHILL, Gilbert A.; PETER, J. Paul Marketing: criando valor para os clientes. São Paulo: Saraiva, 2000.

COBRA, Marcos. Administração de Marketing. São Paulo: Atlas, 1992.

Administração de Vendas. São Paulo: Atlas, 2012.

. Marketing Básico. São Paulo: Atlas, 1997.

FERREL, O.C.; HARTLINE, M.D. Estratégia de marketing. São Paulo: Cengage Learning, 2008.

FUTRELL, Charles M. Vendas: fundamentos e novas práticas de gestão. São Paulo: Saraiva, 2003. 
GUIMARÃES, Reinaldo. A indústria farmacêutica e seus desafios. Cadernos do Desenvolvimento, v. 13, n. 23, p. 183-203, 2018.

KOTLER, Philip. Administração de marketing: análise, planejamento, implementação e controle. 5. ed. São Paulo: Atlas, 2011.

. Marketing de A a Z. Rio de Janeiro: ELsevier, 2003.

KOTLER, Philip; ARMSTRONG, Gary. Princípios de marketing. 12. ed. São Paulo: Pearson Prantice Hall, 2007.

KOTLER, Philip; KELLER, Kevin Lane. Administração de marketing. 12. ed. São Paulo: Pearson Prentice Hall, 2006.

LEVITT, Theodore. A imaginação de marketing. 2. ed. São Paulo: Atlas, 1990.

MALHOTRA, Naresh K. Pesquisa de Marketing. Porto Alegre: Bookman, 2006.

MATTAR, Fauze Najib. Pesquisa de marketing. São Paulo: Atlas, 2001.

Mc DANIEL, Carl. D. Pesquisa de Marketing. São Paulo: Pioneira Thomson Learning, 2003.

OLIVEIRA, D.P.R. Planejamento estratégico: conceitos, metodologias e práticas. São Paulo: Atlas, 1998.

ROESCH, Sylvia Maria Azevedo. Projetos de Estagio e de pesquisa em Administração. São Paulo: Atlas, 1999.

SOUZA, Maria M. S.; BATISTA, José M. M. Indústria farmacêutica brasileira: aspectos atuais. Mostra Científica da Farmácia, v. 5, n. 1, p. 1, 2018.

VERGARA, Sylvia Constant. Projetos e relatórios de pesquisa em administração. São Paulo: Atlas, 2007. 